\title{
Concurrent Use of Benzodiazepines and Antidepressants and the Risk of Motor Vehicle Accident in Older Drivers: A Nested Case-Control Study
}

Jean-Pascal Fournier $\cdot$ Machelle Wilchesky $\cdot$ Valérie Patenaude $\cdot$ Samy Suissa

To view enhanced content go to www.neurologytherapy-open.com

Received: December 12, 2014 / Published online: March 6, 2015

(c) The Author(s) 2015. This article is published with open access at Springerlink.com

\section{ABSTRACT}

Introduction: Aging of the population results in an increase in senior drivers. Elderly are frequently treated with benzodiazepines and antidepressants. The objective of this study was to determine whether the concurrent use of benzodiazepines and antidepressants is associated with motor vehicle accidents (MVAs) in the elderly.

Electronic supplementary material The online version of this article (doi:10.1007/s40120-015-0026-0) contains supplementary material, which is available to authorized users.

J.-P. Fournier · M. Wilchesky · V. Patenaude .

S. Suissa

Centre for Clinical Epidemiology, Lady Davis Institute, Jewish General Hospital, Montreal,

Canada

J.-P. Fournier · S. Suissa $(\bowtie)$

Department of Epidemiology, Biostatistics and Occupational Health, McGill University, Montreal, Canada

e-mail: samy.suissa@mcgill.ca

M. Wilchesky

Donald Berman Maimonides Geriatric Center,

McGill University, Montreal, QC, Canada

M. Wilchesky

Department of Medicine, McGill University,

Montreal, QC, Canada
Methods: This was a nested case-control study within a cohort of drivers aged 67-84 years between 1990 and 2000, identified from the Société de l'Assurance Automobile du Québec and the Régie de l'Assurance Maladie du Québec databases. First cases of MVAs during follow-up were matched with up to ten controls from the cohort. Odds ratios (ORs) for the association between MVA and the use of benzodiazepines and antidepressants were estimated using conditional logistic regression.

Results: The cohort included 373,818 drivers, with 74,503 MVA cases matched with 744,663 controls. The risk of MVA was higher in current users of long-acting benzodiazepines [OR 1.23; 95\% confidence interval (CI) 1.16-1.29] than in current users of short-acting benzodiazepines (OR 1.05; 95\% CI 1.02-1.08). The risk of MVA was increased in current users of selective serotonin reuptake inhibitors (SSRIs; OR 1.13; 95\% CI 1.04-1.22), while it was not in current users of tricyclic antidepressants (TCAs; OR 1.04; 95\% CI 0.96-1.14). The highest ORs of MVA were observed in long-acting benzodiazepines users concurrently using SSRIs (OR 1.37; 95\% CI 1.07-1.77, $P$ value for interaction $=0.964)$ or TCAs $(\mathrm{OR} 1.54 ; 95 \% \mathrm{CI}$ $1.21-1.95, P$ value for interaction $=0.077$ ). 
Conclusion: Use of long-acting benzodiazepines is associated with an increased risk of MVA in the elderly, particularly in those concurrently using SSRIs or TCAs.

Keywords: Aged; Antidepressants; Automobile driving; Benzodiazepines; Drug interactions

\section{INTRODUCTION}

Aging of the population leads to an increase in senior drivers. It is expected that by the year 2030 , drivers older than 65 years of age will be involved in 1 out of 4 fatal motor vehicles accidents (MVAs) [1]. Increasing drug exposure is an important factor linked to an increase in the risk of MVA in the elderly [2]. Psychotropic drugs have particularly been under scrutiny for the recent years, with special focus on benzodiazepines and antidepressants [3]. Benzodiazepines have been identified with the most consistent increase in risk of MVA in the elderly [4-8]. Results of large case-control studies suggested that long-acting benzodiazepines are associated with greater risk of MVA than short-acting benzodiazepines in elderly drivers $[5,6]$, similarly to what has been previously demonstrated in the younger population. Antidepressant use has also been associated with an increased risk of MVA $[4,7$, 9-12]. The increase in risk has been initially observed for tricyclic antidepressants (TCAs) [4]. Further studies confirmed this increase in risk for newer antidepressants, including selective serotonin reuptake inhibitors (SSRIs) [10-12].

Benzodiazepines and antidepressants are often indicated to treat depression or anxiety disorders [13, 14], and antidepressant use has been on the rise among the elderly during the last decade $[15,16]$. From a pharmacological perspective, it is plausible that the concurrent use of both benzodiazepines and antidepressants may increase the risk of MVA. Antidepressants have the potential to aggravate psychomotor impairment and sedation induced by benzodiazepines through pharmacodynamics interactions or pharmacokinetic interactions [17]. However, few studies have focused on concomitant use of benzodiazepines and antidepressants and driving abilities in the elderly [4, 11]. Ray et al. [4] showed a $110 \%$ increase in MVAs in older drivers taking both benzodiazepines and TCAs, that was not significantly different from users of benzodiazepines or TCAs alone. On the other hand, Rapoport et al. [11] reported that in older drivers using antidepressants, concomitant use of benzodiazepines was associated with a $23 \%$ increase of at-fault MVAs, compared to antidepressants alone.

Given the limited safety data on the combinations of the aforementioned drugs, we conducted a large population-based study to determine whether the concurrent use of benzodiazepines and antidepressants is associated with MVAs in the elderly.

\section{METHODS}

\section{Data Source}

The study was conducted using the Société de l'Assurance Automobile du Québec (SAAQ) and the Régie de l'Assurance Maladie du Québec (RAMQ) databases, from the province of Quebec, Canada.

The SAAQ databases record information about drivers, vehicles, and accidents, and have been initially designed for administrative purposes. A specific file contains MVA report 
forms that are completed both for crashes involving injury and those with material damage only. They contain information regarding the accident (date, time, location, and type of the accident, weather and road conditions, number and type of vehicles involved, estimated amount of vehicle and property damage), as well as persons involved (vehicle occupied, position in car, seatbelt use, nature of injuries, health care number, and hospital to which injured were transported). Police officers are required to complete this report for accidents involving physical harm, where material damages exceed $\$ 1,000$ in value, or where a crime or offense was committed.

The RAMQ databases comprise data on all residents of the province of Quebec covered by the provincial health insurance plan ( $>7$ million people). These databases capture all physician visits, procedures, hospitalizations, patient demographics, and pharmacy claims for prescription medications. Variables contained within the prescription database include drug name, date of dispensing, number of units administered, dose per unit, and duration of prescribed treatment.

The linkage between SAAQ databases and RAMQ databases was performed using either the social insurance number or a probability match that used the name, address, and date of birth. The linkage between SAAQ and RAMQ databases has already been efficiently used in previous studies $[5,12,18]$.

\section{Design}

We conducted a nested case-control study within a cohort of drivers between the ages of 67 and 84 years in the study period June 1 , 1990 to May 31, 2000. We thus extended by 7 years the study period of a previous cohort study conducted in the same databases [5]. All subjects had to have a valid driver's license. The cohort was restricted to subjects using a RAMQ service (medical or pharmaceutical) at least once per year during their follow-up, to ensure that all cohort subjects were residing in the province of Quebec during the whole study period. Cohort entry was defined as June 1, 1990, the date of a subject's 67 th birthday, or the day that a valid driver's license was issued, whichever occurred last. All subjects were followed up until May 31, 2000, their 84th birthday, expiry of their driver's license, or death, whichever occurred first.

\section{Cases and Controls}

Cases were all first MVAs during follow-up, including injurious accidents and accidents with property damage only. Cases were matched to up to ten controls on sex, age at cohort entry, and duration of follow-up. Controls were randomly selected from the risk set made up of all members of the cohort who were at risk for the outcome at the time of the index date (date of accident). In accord with basic principles, subjects may have been selected more than once, but on different days, of their follow-up.

\section{Exposure}

Exposure to medications was assessed in the 2 years prior to the index date using both information pertaining to the date a medication was dispensed, and duration of treatment as recorded in the medication prescription file of the RAMQ databases. The use of medications was classified into four mutually exclusives categories: (1) new use, if the medication prescription was issued in the 30 days before index date only, and supply 
lasted at least until the index date; (2) current, not new use, if the medication prescription was issued earlier than 30 days before index date and supply lasted at least until the index date; (3) past use, consisting of other prescription patterns; and (4) no use, which was the reference category for all analyses. For secondary analyses with small group sizes, new use and current, not new use were combined into a single current use category.

Antidepressants were studied as an all-inclusive drug category, and then according to the three following classes: TCAs (amitriptyline, amoxapine, clomipramine, desipramine, doxepin, imipramine, maprotiline, nortriptyline, protriptyline, trimipramine), SSRIs (citalopram, fluoxetine, fluvoxamine, paroxetine, sertraline) and other antidepressants (bupropion, moclobemide, nefazodone, phenelzine, tranylcypromine, trazodone, venlafaxine). Benzodiazepines were studied as an all-inclusive drug category, and then classified as long-acting benzodiazepines (chlordiazepoxide, clobazam, clonazepam, clorazepate, diazepam, flurazepam, and nitrazepam) and short-acting benzodiazepines (alprazolam, bromazepam, lorazepam, midazolam, oxazepam, temazepam, and triazolam).

\section{Sensitivity Analysis}

The first sensitivity analysis restricted the outcome definition to injurious MVAs only, to assess the risk of drug use on the risk of these serious events. In a second sensitivity analysis, the exposure duration associated with the last prescription for an antidepressant or a benzodiazepine was extended by 30 days, to account for the potential sustained effects of drug use occurring as a result of their pharmacokinetic properties (e.g., the elimination half-life) of these drugs.

\section{Statistical Analysis}

Conditional logistic regression models were used to compute odds ratios (ORs) with their 95\% confidence interval (CI) for associations between the use of benzodiazepines and antidepressants and the MVAs, which, for the time-matched nested case-control method used here, provides unbiased estimates of the rate ratio and their 95\% CI [19]. In addition to matching on sex, age at cohort entry, and duration of follow-up, potential confounding was addressed by adjusting the models for accidents which occurred during the five-year period prior to cohort entry, the number of general practice visits, the number of drug categories concomitantly used in the year prior to index date between cardiovascular drugs, glucoselowering drugs, anti-infective agents and bronchodilators (as a proxy of comorbidity), the number of overall distinct drugs dispensed during the year prior to index date, and the use of other central nervous system drugs (anti-Parkinson drugs, opioids, anticonvulsants, other) in the 90 days prior to index date.

The concurrent use of benzodiazepines and antidepressants was estimated using interaction terms for each of the combinations of benzodiazepines and antidepressants, and presented by stratified analyses according to type of benzodiazepines, antidepressants, and type of use [none, past, current (new and current not new, as stated above)).

All computations were performed using the SAS software version 9.3 (SAS Institute Inc., Cary, NC, USA).

\section{Compliance with Ethics Guidelines}

The study protocol was approved by the Research Ethics Committee of the Jewish General Hospital, Montreal, Canada. All data used in this study were anonymized. 


\section{RESULTS}

\section{Characteristics of Cases and Controls}

From the study cohort of 373,818 eligible drivers aged $67-84$ years, 74,503 cases of first MVAs were identified, including 12,534 causing injuries (16.8\%) and 441 causing fatalities $(0.6 \%)$. These cases were matched to 744,663 controls (Fig. 1). Table 1 presents the general characteristics and the distribution of comorbidities and comedications among cases and controls. Cases were more likely to have had a MVA in the 5 years preceding cohort entry than controls. Cases were also more likely to have more general practice consultations before index date, and were exposed to more drugs than controls.

\section{MVAs and Use of Benzodiazepines or Antidepressants}

Table 2 presents the crude and adjusted OR for MVA associated with the use of benzodiazepines

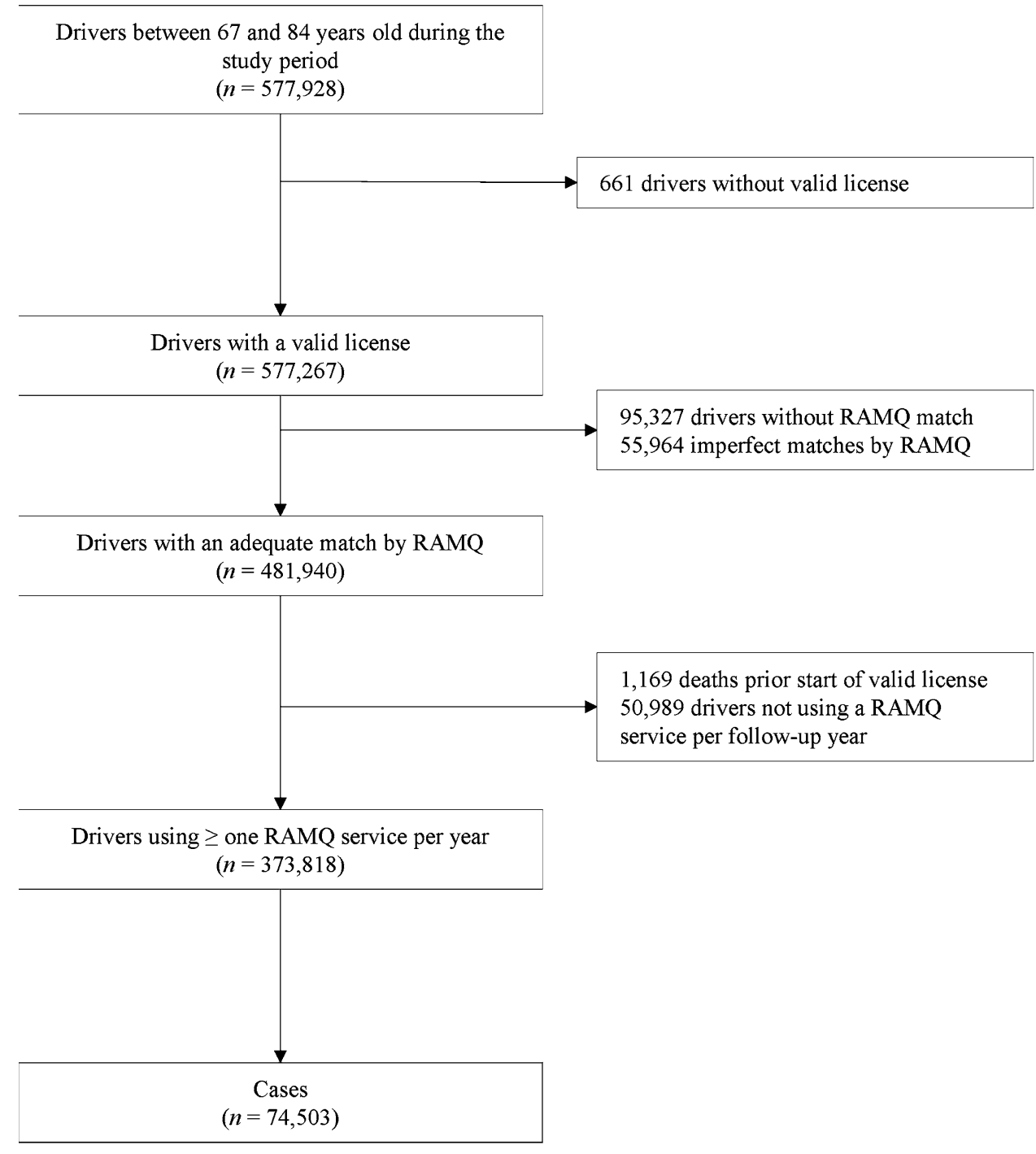

Fig. 1 Flowchart of study subjects. RAMQ Régie de l'Assurance Maladie du Québec 
Table 1 Characteristics of motor vehicle accident cases and matched controls

\begin{tabular}{|c|c|c|}
\hline Characteristics & Cases $(74,503)$ & Controls $(744,663)$ \\
\hline \multicolumn{3}{|l|}{ Age, $n(\%)$} \\
\hline $67-69$ years & $23,764(31.9)$ & $237,640(31.9)$ \\
\hline $70-72$ years & $18,976(25.5)$ & $189,760(25.5)$ \\
\hline $73-75$ years & $13,270(17.8)$ & $132,700(17.8)$ \\
\hline$>75$ years & $18,493(24.8)$ & $184,563(24.8)$ \\
\hline Follow-up, mean $(\mathrm{SD})$ years & $3.05(2.4)$ & $3.05(2.4)$ \\
\hline Male, $n(\%)$ & $60,567(81.3)$ & $605,467(81.3)$ \\
\hline \multicolumn{3}{|c|}{ Accidents in the 5 years prior cohort entry, $n(\%)$} \\
\hline Causing a fatality & $51(0.07)$ & $394(0.05)$ \\
\hline Causing severe injuries & $633(0.8)$ & $4,512(0.6)$ \\
\hline Causing light injuries & $4,539(6.1)$ & $32,143(4.3)$ \\
\hline Causing $<\$ 500$ material damage & $4,820(6.5)$ & $31,450(4.2)$ \\
\hline Causing $\geq \$ 500$ material damage & $17,771(23.8)$ & $126,721(17.0)$ \\
\hline \multicolumn{3}{|c|}{ Number of general practice visits, $n(\%)^{\mathrm{a}}$} \\
\hline 0 & $7,271(9.8)$ & $80,445(10.8)$ \\
\hline $1-3$ & $24,114(32.4)$ & $253,198(34.0)$ \\
\hline $4-9$ & $29,689(39.8)$ & $289,772(38.9)$ \\
\hline$\geq 10$ & $13,429(18.0)$ & $121,248(16.3)$ \\
\hline
\end{tabular}

Number of drug categories among cardiovascular drugs, glucose-lowering drugs, anti-infective agents and bronchodilators, $n(\%)^{\mathrm{a}}$

\begin{tabular}{lll}
0 & $25,242(33.9)$ & $257,260(34.5)$ \\
1 & $32,368(43.4)$ & $328,476(44.1)$ \\
2 & $13,324(17.9)$ & $127,118(17.1)$ \\
3 & $3,365(4.5)$ & $30,139(4.0)$ \\
4 & $204(0.3)$ & $1,670(0.2)$ \\
Number of distinct drugs, $n(\%)^{\mathrm{a}}$ & & $180,344(24.2)$ \\
$0-2$ & $16,961(22.8)$ & $233,738(31.4)$ \\
$3-5$ & $22,707(30.5)$ & $202,128(27.1)$ \\
$6-9$ & $20,788(27.9)$ & $84,510(11.3)$ \\
$10-13$ & $9,048(12.1)$ & $43,943(5.9)$ \\
$>13$ & $4,999(6.7)$ & \\
Use of central nervous system drugs, $n(\%)^{\mathrm{b}}$ & & $8,151(1.1)$ \\
Anticonvulsants & $891(1.2)$ & $4,067(0.5)$ \\
Anti-Parkinson drugs & $373(0.5)$ & $5,646(0.8)$ \\
Opioid & $494(0.7)$ & $5,192(0.7)$ \\
Other central nervous system drugs & $559(0.8)$ & \\
\hline
\end{tabular}

${ }^{\text {a }}$ During the year prior to the index date

b Dispensed during the 90-day period prior to the index date 
or antidepressants. The risk of MVA was higher in current, not new users of long-acting benzodiazepines (adjusted OR 1.23; 95\% CI 1.16-1.29) than short-acting benzodiazepines (adjusted OR 1.05; 95\% CI 1.02-1.08). The risk of MVA was increased in SSRIs users (new users: adjusted OR 1.25; 95\% CI 1.00-1.55, current, not new users: adjusted OR 1.13; 95\% CI 1.04-1.22), while there was no observed increased risk among TCAs users (new users: adjusted OR 0.93; 95\% CI 0.67-1.28, current, not new users: adjusted OR 1.04; 95\% CI 0.96-1.14).

\section{MVAs and Concurrent Use of Benzodiazepines and Antidepressants}

Tables 3 and 4 present the crude and adjusted estimates of effect for the risk of MVA associated with concurrent use of benzodiazepines and antidepressants. Among users of antidepressants, the risk of MVA was increased in concurrent users of long-acting benzodiazepines (adjusted OR 1.43; 95\% CI 1.21-1.69) and in concurrent users of short-acting benzodiazepines (adjusted OR 1.19; 95\% CI 1.06-1.34), with no statistically significant interaction $(P$ values for interaction $=0.325$ and 0.393 , respectively; Table 3). Among users of long-acting benzodiazepines, there was an increased risk of MVA in both concurrent users of SSRIs (adjusted OR 1.37; 95\% CI 1.07-1.77, $P$ value for interaction $=0.964$ ) and concurrent users of TCAs (adjusted OR 1.54; 95\% CI 1.21-1.95, $P$ value for interaction $=0.077$; Table 4 ) .

\section{Sensitivity Analysis}

Restricting the analysis to injurious MVAs identified 18,403 cases that were matched to 183,933 controls, and led to similar results [Tables S1, S2, S3, and S4 in the electronic supplementary material (ESM)]. Extending the last benzodiazepine or antidepressant exposure period by an additional 30 days resulted in little modification of the estimates (Tables S5, S6, and S7 in the ESM).

\section{DISCUSSION}

We investigated the association between the concurrent use of benzodiazepines and antidepressants and the risk of MVA in the elderly in this large population-based study. Our results reaffirm that the increased risk associated with the current use of long-acting benzodiazepines is greater than current use of short-acting benzodiazepines (23 and 5\% increased risk, respectively). In concurrent users of benzodiazepines and antidepressants, the increased risk of MVA was the highest in concurrent users of long-acting benzodiazepines and SSRIs (37\% increased risk) or TCAs (54\% increased risk), although no statistically significant interactions were found.

The study results are concordant with a previous study conducted in the same databases 20 years ago reporting a $26 \%$ increased risk for elderly continuously using long-acting benzodiazepines, while no significant increased risk was observed in users of short-acting benzodiazepines [5]. Neutel [6] also reported that the increased risk of MVA observed in drivers aged over 60 years was the highest in users of long-acting benzodiazepines. Conversely, two other epidemiological studies that were limited by statistical power did not observe a significant association between use of long-acting benzodiazepines and MVAs in elderly drivers $[9,20]$. Of note, although the increase in risk of MVA is deemed highest in the first days of use among users of benzodiazepines $[5,6]$, we observed no significant increase in risk in new users of benzodiazepines. We have no 
Table 2 Odds ratios of motor vehicle accidents (any) associated with exposure to use of benzodiazepines or antidepressants

\begin{tabular}{|c|c|c|c|c|}
\hline \multirow[t]{2}{*}{ Exposure } & \multirow{2}{*}{$\begin{array}{l}\text { Cases } \\
(74,503)\end{array}$} & \multirow{2}{*}{$\begin{array}{l}\text { Controls } \\
(744,663)\end{array}$} & \multicolumn{2}{|c|}{ Odds Ratio (95\% CI) } \\
\hline & & & Crude & Adjusted $^{a}$ \\
\hline \multicolumn{5}{|l|}{ Benzodiazepines } \\
\hline \multicolumn{5}{|l|}{ Long-acting } \\
\hline None & $68,619(92.1)$ & $693,839(93.2)$ & 1.00 (reference) & 1.00 (reference) \\
\hline New & $87(0.1)$ & $807(0.1)$ & $1.09(0.88-1.36)$ & $1.03(0.83-1.29)$ \\
\hline Current, not new & $1,718(2.3)$ & $13,463(1.8)$ & $1.29(1.23-1.36)$ & $1.23(1.16-1.29)$ \\
\hline Past only & $4,079(5.5)$ & $36,554(4.9)$ & $1.13(1.09-1.17)$ & $1.07(1.04-1.11)$ \\
\hline \multicolumn{5}{|l|}{ Short-acting } \\
\hline None & $58,630(78.7)$ & $597,030(80.2)$ & 1.00 (reference) & 1.00 (reference) \\
\hline New & $138(0.2)$ & $1,480(0.20)$ & $0.96(0.80-1.14)$ & $0.93(0.78-1.10)$ \\
\hline Current, not new & $5,123(6.8)$ & $47,502(6.4)$ & $1.11(1.07-1.14)$ & $1.05(1.02-1.08)$ \\
\hline Past only & $10,612(14.2)$ & $98,651(13.2)$ & $1.10(1.08-1.13)$ & $1.05(1.03-1.08)$ \\
\hline \multicolumn{5}{|l|}{ Antidepressants } \\
\hline \multicolumn{5}{|c|}{ Selective serotonin reuptake inhibitors } \\
\hline None & $72,173(96.9)$ & $724,276(97.3)$ & 1.00 (reference) & 1.00 (reference) \\
\hline New & $93(0.1)$ & $690(0.09)$ & $1.35(1.09-1.68)$ & $1.25(1.00-1.55)$ \\
\hline Current, not new & $759(1.0)$ & $6,166(0.8)$ & $1.24(1.15-1.33)$ & $1.13(1.04-1.22)$ \\
\hline Past only & $1,478(2.0)$ & $13,531(1.8)$ & $1.10(1.04-1.16)$ & $1.00(0.95-1.06)$ \\
\hline \multicolumn{5}{|c|}{ Tricyclic antidepressants } \\
\hline None & $72,264(97.0)$ & $724,937(97.3)$ & 1.00 (reference) & 1.00 (reference) \\
\hline New & $41(0.06)$ & $418(0.06)$ & $0.98(0.71-1.36)$ & $0.93(0.67-1.28)$ \\
\hline Current, not new & $552(0.7)$ & $4,855(0.6)$ & $1.14(1.05-1.25)$ & $1.04(0.96-1.14)$ \\
\hline Past only & $1,646(2.2)$ & $14,453(1.9)$ & $1.14(1.09-1.20)$ & $1.05(0.99-1.10)$ \\
\hline \multicolumn{5}{|l|}{ Other antidepressants } \\
\hline None & $73,705(98.9)$ & $738,034(99.1)$ & 1.00 (reference) & 1.00 (reference) \\
\hline New & $28(0.04)$ & $233(0.03)$ & $1.20(0.81-1.78)$ & $1.10(0.74-1.63)$ \\
\hline Current, not new & $209(0.3)$ & $1,722(0.2)$ & $1.22(1.05-1.41)$ & $1.09(0.94-1.26)$ \\
\hline Past only & $561(0.7)$ & $4,674(0.6)$ & $1.20(1.10-1.31)$ & $1.07(0.98-1.17)$ \\
\hline
\end{tabular}

Values are numbers (percentages) unless stated otherwise

a Adjusted for variables in Table 1

CI confidence interval 
Table 3 Odds ratios of motor vehicle accidents (any) associated with exposure to concurrent use of benzodiazepines and antidepressants combination

\begin{tabular}{|c|c|c|c|c|}
\hline \multirow[t]{2}{*}{ Exposure } & \multirow{2}{*}{$\begin{array}{l}\text { Cases } \\
(74,503)\end{array}$} & \multirow{2}{*}{$\begin{array}{l}\text { Controls } \\
(744,663)\end{array}$} & \multicolumn{2}{|c|}{ Odds ratio $(95 \% \mathrm{CI})$} \\
\hline & & & $\overline{\text { Crude }}$ & Adjusted $^{a}$ \\
\hline \multicolumn{5}{|l|}{ Benzodiazepines (any) and antidepressants } \\
\hline Neither & $52,819(70.9)$ & $544,069(73.1)$ & 1.00 (reference) & 1.00 (reference) \\
\hline Current benzodiazepine, current antidepressant $\mathrm{t}^{\mathrm{b}}$ & $442(0.6)$ & $3,302(0.4)$ & $1.39(1.26-1.54)$ & $1.28(1.16-1.42)$ \\
\hline Current benzodiazepine, no antidepressant $^{\mathrm{b}}$ & $5,832(7.8)$ & $53,675(7.2)$ & $1.13(1.10-1.16)$ & $1.08(1.05-1.12)$ \\
\hline No benzodiazepine, current antidepressant ${ }^{\mathrm{b}}$ & $718(1.0)$ & $6,712(0.9)$ & $1.10(1.02-1.19)$ & $1.04(0.96-1.13)$ \\
\hline Other combinations & $14,692(19.7)$ & $136,905(18.4)$ & $1.11(1.09-1.13)$ & $1.07(1.05-1.09)$ \\
\hline \multicolumn{5}{|l|}{ Long-acting benzodiazepines and antidepressants } \\
\hline Neither & $64,971(87.2)$ & $660,856(88.7)$ & 1.00 (reference) & 1.00 (reference) \\
\hline $\begin{array}{l}\text { Current long-acting benzodiazepines, current } \\
\text { antidepressant }^{\text {b }}\end{array}$ & $163(0.2)$ & $1,068(0.1)$ & $1.56(1.32-1.84)$ & $1.43(1.21-1.69)$ \\
\hline $\begin{array}{l}\text { Current long-acting benzodiazepines, no } \\
\text { antidepressant }^{\text {b }}\end{array}$ & $1,469(2.0)$ & $11,896(1.6)$ & $1.26(1.19-1.33)$ & $1.21(1.14-1.28)$ \\
\hline $\begin{array}{l}\text { No long-acting benzodiazepine, current } \\
\text { antidepressant }^{\mathrm{b}}\end{array}$ & $1,230(1.6)$ & $10,923(1.5)$ & $1.15(1.08-1.22)$ & $1.08(1.01-1.14)$ \\
\hline Other combinations & $6,670(8.9)$ & $59,920(8.0)$ & $1.13(1.10-1.16)$ & $1.08(1.05-1.11)$ \\
\hline \multicolumn{5}{|l|}{ Short-acting benzodiazepines and antidepressants } \\
\hline Neither & $64,971(87.2)$ & $660,856(88.7)$ & 1.00 (reference) & 1.00 (reference) \\
\hline $\begin{array}{l}\text { Current short-acting benzodiazepines, current } \\
\text { antidepressant }^{\mathrm{b}}\end{array}$ & $304(0.4)$ & $2,373(0.3)$ & $1.31(1.16-1.47)$ & $1.19(1.06-1.34)$ \\
\hline $\begin{array}{l}\text { Current short-acting benzodiazepines, no } \\
\text { antidepressant }^{\mathrm{b}}\end{array}$ & $523(0.7)$ & $4,294(0.6)$ & $1.24(1.13-1.36)$ & $1.10(0.99-1.22)$ \\
\hline $\begin{array}{l}\text { No short-acting benzodiazepines, current } \\
\text { antidepressant }{ }^{\mathrm{b}}\end{array}$ & $911(1.2)$ & $8,183(1.1)$ & $1.13(1.06-1.21)$ & $1.06(0.99-1.14)$ \\
\hline Other combinations & $7,794(10.5)$ & $68,957(9.3)$ & $1.15(1.12-1.18)$ & $1.06(1.02-1.11)$ \\
\hline
\end{tabular}

Values are numbers (percentages) unless stated otherwise

a Adjusted for variables in Table 1

b New users and current, not new users were grouped in current users, because of small group size

CI confidence interval

specific explanation for this discrepancy, which may be driven by unmeasured confounders.

Regarding the risk associated with the use of antidepressants, our results reaffirm the increased risk previously observed with SSRIs
[10-12]. The non-significant OR observed in our study associated with TCAs use is discordant with the increased risk observed 20 years ago [4], but concordant with a more recent study [11]. This may either be explained by a temporal 
Table 4 Odds ratios of motor vehicle accidents (any) associated with exposure to concurrent use of long-acting benzodiazepine and antidepressants combination

\begin{tabular}{|c|c|c|c|c|}
\hline \multirow[t]{2}{*}{ Exposure } & \multirow{2}{*}{$\begin{array}{l}\text { Cases } \\
(74,503)\end{array}$} & \multirow{2}{*}{$\begin{array}{l}\text { Controls } \\
(744,663)\end{array}$} & \multicolumn{2}{|c|}{ Odds ratio $(95 \% \mathrm{CI})$} \\
\hline & & & Crude & Adjusted $^{a}$ \\
\hline \multicolumn{5}{|l|}{ Long-acting benzodiazepines and SSRIs (any) } \\
\hline Neither & $66,824(89.7)$ & $677,643(91.0)$ & 1.00 (reference) & 1.00 (reference) \\
\hline $\begin{array}{l}\text { Current long-acting benzodiazepines, current } \\
\text { SSRI }^{\text {b }}\end{array}$ & $69(0.09)$ & $456(0.06)$ & $1.54(1.20-1.98)$ & $1.37(1.07-1.77)$ \\
\hline Current long-acting benzodiazepines, no SSRI ${ }^{\mathrm{b}}$ & $1,656(2.2)$ & $13,194(1.8)$ & $1.27(1.21-1.34)$ & $1.22(1.15-1.28)$ \\
\hline No long-acting benzodiazepine, current SSRI ${ }^{\mathrm{b}}$ & $638(0.9)$ & $5,493(0.7)$ & $1.18(1.08-1.28)$ & $1.10(1.01-1.19)$ \\
\hline Other combinations & $5,316(7.1)$ & $47,877(6.4)$ & $1.13(1.09-1.16)$ & $1.07(1.03-1.10)$ \\
\hline \multicolumn{5}{|l|}{ Long-acting benzodiazepines and TCAs (any) } \\
\hline Neither & $66,937(89.8)$ & $678,609(91.1)$ & 1.00 (reference) & 1.00 (reference) \\
\hline $\begin{array}{l}\text { Current long-acting benzodiazepines, current } \\
\text { TCA }^{\text {b }}\end{array}$ & $79(0.1)$ & $489(0.07)$ & $1.65(1.30-2.09)$ & $1.54(1.21-1.95)$ \\
\hline Current long-acting benzodiazepines, no $\mathrm{TCA}^{\mathrm{b}}$ & $1,608(2.2)$ & $12,916(1.7)$ & $1.26(1.20-1.33)$ & $1.21(1.14-1.27)$ \\
\hline No long-acting benzodiazepine, current $\mathrm{TCA}^{\mathrm{b}}$ & $435(0.6)$ & $4,036(0.5)$ & $1.10(0.99-1.21)$ & $1.03(0.93-1.14)$ \\
\hline Other combinations & $5,444(7.3)$ & $48,613(6.5)$ & $1.14(1.10-1.17)$ & $1.08(1.05-1.11)$ \\
\hline \multicolumn{5}{|l|}{ Long-acting BDZ and other antidepressants } \\
\hline Neither & $68,032(91.3)$ & $688,741(92.5)$ & 1.00 (reference) & 1.00 (reference) \\
\hline $\begin{array}{l}\text { Current long-acting benzodiazepines, current } \\
\text { other antidepressant }^{\text {b }}\end{array}$ & $24(0.03)$ & $145(0.02)$ & $1.68(1.09-2.59)$ & $1.49(0.97-2.31)$ \\
\hline $\begin{array}{l}\text { Current long-acting benzodiazepines, no other } \\
\text { antidepressant }^{\mathrm{b}}\end{array}$ & $1,739(2.3)$ & $13,841(1.9)$ & $1.27(1.21-1.34)$ & $1.21(1.15-1.28)$ \\
\hline $\begin{array}{l}\text { No long-acting benzodiazepine, current other } \\
\text { antidepressant }{ }^{\mathrm{b}}\end{array}$ & $180(0.2)$ & $1,511(0.2)$ & $1.21(1.03-1.41)$ & $1.11(0.95-1.29)$ \\
\hline Other combinations & $4,528(6.1)$ & $40,425(5.4)$ & $1.14(1.10-1.17)$ & $1.07(1.04-1.11)$ \\
\hline
\end{tabular}

Values are numbers (percentages) unless stated otherwise

${ }^{\text {a }}$ Adjusted for variables in Table 1

b New users and current, not new users were grouped in current users, because of small group size

$C I$ confidence interval, SSRI selective serotonin reuptake inhibitors, TCA tricyclic antidepressants

trend in prescribing which have favored SSRIs over TCAs in recent years, or possibly by an increased propensity in patients using TCAs (as opposed to SSRIs) to refrain from driving.

In concurrent users of antidepressants and benzodiazepines, the increased risk of MVA was the highest in concurrent users of longacting benzodiazepines and TCAs (54\% increased risk), with the interaction almost attaining statistical significance. This result suggests that the $23 \%$ increase of at-fault MVAs previously observed in concurrent users 
of both TCAs and benzodiazepines, compared to those observed in users of TCAs alone [11] may be largely attributable to long-acting benzodiazepine use. Our data indicate a potential for synergistic interaction between TCAs and long-acting benzodiazepines, through increases in sedation and psychomotor impairment, which would need to be confirmed in further studies.

Numerous experimental studies have assessed the impact of the use of benzodiazepines or antidepressants on psychomotor and driving skills [21]. Among these, few have focused on elderly subjects [2224]. Although these studies were limited by small sample sizes, their results suggested that the elderly may not be more susceptible when compared with younger individuals to psychomotor and driving impairment induced by benzodiazepines $[23,24]$. In one study, for example, no acute driving impairment was observed in 12 elderly subjects administrated $50 \mathrm{mg}$ of imipramine, whereas a significant impairment was observed in 12 younger subjects [22]. In addition, only one study assessed the impact of concomitant use of antidepressants or benzodiazepines on psychomotor skills, but focused on young subjects only [25]. In 24 healthy young subjects randomly assigned to TCAs and diazepam (alone or in combination) or placebo, a significant impairment was observed in subjects administered combinations of TCAs and diazepam for up to $6 \mathrm{~h}$, whereas when these drugs were administered alone there were no such effects [25]. To our knowledge, no similar study has been conducted in elderly subjects, and no study has assessed the psychomotor abilities or driving abilities of subjects chronically exposed to these drug combinations.
This study has a number of strengths. First, the use of the linked RAMQ and SAAQ databases enabled us to constitute a large populationbased cohort of elderly drivers, and to account for important potential confounders, such as comorbidity or use of other central nervous system drugs. In addition, results of our sensitivity analyses produced risk estimates consistent with our primary analyses results.

This study does have limitations. First, RAMQ databases record pharmacy claims for prescription medications, and it is uncertain whether patients adhered to their prescribed treatment. Moreover, no information on the timing of drug intake is available. Potential differences for morning or bedtime intake of benzodiazepines or TCAs (if used for sleep disorders) could thus not be assessed. In addition, the period of time immediately following either the introduction to or a change of dosage in benzodiazepines or antidepressants is of special interest among elderly patients. It has been shown that there exists a 50\% increased risk of injurious MVAs within the 7 days following the initiation of long-acting benzodiazepines [5]. Due to insufficient power, however, we were unable to assess the possibility of risk modification for new users of benzodiazepines in current users of antidepressant (and vice versa). Results of this study should also be interpreted with caution, since confounding by indication or channeling cannot be ruled out: it is uncertain if the observed increased risk in elderly drivers treated with combinations of antidepressants and benzodiazepines is directly related to their pharmacological effects, or whether this increased risk is related to more severe underlying depression/anxiety disorder or unmeasured patients' characteristics. Finally, given the observational nature of the study, 
the potential for residual confounding needs to be considered.

\section{CONCLUSIONS}

Assessment of MVA risk in the elderly is challenging. We confirmed that use of longacting benzodiazepines or SSRIs may be associated with an increased risk of both injurious and non-injurious MVA in the elderly. An increase in risk was also observed in drivers concurrently exposed to benzodiazepines and antidepressant (whether SSRIs or TCAs). Older patients should be cautioned about these risks, and advised regarding their driving activity while under treatment with long-acting benzodiazepines and SSRIs or TCAs.

\section{ACKNOWLEDGMENTS}

The authors thank the staff of the Régie de l'Assurance Maladie du Québec (RAMQ) and of the Société de l'Assurance Automobile du Québec (SAAQ) for their expertise and assistance in obtaining the databases. This research was funded by a grant from the Canadian Institutes of Health Research (CIHR). The funder had no role in the study. All named authors meet the International Committee of Medical Journal Editors (ICMJE) criteria for authorship for this manuscript, take responsibility for the integrity of the work as a whole, and have given final approval for the version to be published.

Conflict of interest. Jean-Pascal Fournier, Machelle Wilchesky, Valérie Patenaude, and Samy Suissa have no conflict of interest to declare.
Compliance with ethics guidelines. The study protocol was approved by the Research Ethics Committee of the Jewish General Hospital, Montreal, Canada. All data used in this study were anonymized.

Open Access. This article is distributed under the terms of the Creative Commons Attribution Noncommercial License which permits any noncommercial use, distribution, and reproduction in any medium, provided the original author(s) and the source are credited.

\section{REFERENCES}

1. Lyman S, Ferguson SA, Braver ER, Williams AF. Older driver involvements in police reported crashes and fatal crashes: trends and projections. Inj Prev. 2002;8:116-20.

2. Monárrez-Espino J, Laflamme L, Elling B, Möller J. Number of medications and road traffic crashes in senior Swedish drivers: a population-based matched case-control study. Inj Prev. 2014;20:81-7.

3. Cooper L, Meuleners LB, Duke J, Jancey J, Hildebrand J. Psychotropic medications and crash risk in older drivers a review of the literature. Asia Pac J Public Health. 2011;23:443-57.

4. Ray WA, Fought RL, Decker MD. Psychoactive drugs and the risk of injurious motor vehicle crashes in elderly drivers. Am J Epidemiol. 1992;136:873-83.

5. Hemmelgarn B, Suissa S, Huang A, Boivin JF, Pinard $\mathrm{G}$. Benzodiazepine use and the risk of motor vehicle crash in the elderly. JAMA. 1997;278:27-31.

6. Neutel I. Benzodiazepine-related traffic accidents in young and elderly drivers. Hum Psychopharmacol. 1998;13:S115-23.

7. Meuleners LB, Duke J, Lee AH, Palamara P, Hildebrand J, Ng JQ. Psychoactive medications and crash involvement requiring hospitalization for older drivers: a population-based study. J Am Geriatr Soc. 2011;59:1575-80.

8. Johnell K, Laflamme L, Möller J, Monárrez-Espino J. The role of marital status in the association between benzodiazepines, psychotropics and injurious road 
traffic crashes: a register-based nationwide study of senior drivers in Sweden. PLoS One. 2014;9:e86742.

9. Leveille SG, Buchner DM, Koepsell TD, McCloskey LW, Wolf ME, Wagner EH. Psychoactive medications and injurious motor vehicle collisions involving older drivers. Epidemiology. 1994;5:591-8.

10. Bramness JG, Skurtveit S, Neutel CI, Mørland J, Engeland A. Minor increase in risk of road traffic accidents after prescriptions of antidepressants: a study of population registry data in Norway. J Clin Psychiatry. 2008;69:1099-103.

11. Rapoport MJ, Zagorski B, Seitz D, Herrmann N, Molnar F, Redelmeier DA. At-fault motor vehicle crash risk in elderly patients treated with antidepressants. Am J Geriatr Psychiatry. 2011;19:998-1006.

12. Orriols L, Wilchesky M, Lagarde E, Suissa S. Prescription of antidepressants and the risk of road traffic crash in the elderly: a case-crossover study. Br J Clin Pharmacol. 2013;76:810-5.

13. Johnell K, Fastbom J. The use of benzodiazepines and related drugs amongst older people in Sweden: associated factors and concomitant use of other psychotropics. Int J Geriatr Psychiatry. 2009;24:731-8.

14. Nishtala PS, McLachlan AJ, Bell JS, Chen TF. Determinants of antidepressant medication prescribing in elderly residents of aged care homes in Australia: a retrospective study. Am J Geriatr Pharmacother. 2009;7:210-9.

15. Smith AJ, Tett SE. How do different age groups use benzodiazepines and antidepressants? Analysis of an Australian administrative database, 2003-6. Drugs Aging. 2009;26:113-22.

16. Parabiaghi A, Franchi C, Tettamanti $M$, et al. Antidepressants utilization among elderly in Lombardy from 2000 to 2007: dispensing trends and appropriateness. Eur J Clin Pharmacol. 2011;67:1077-83.
17. Baxter K, Preston CL, Stockley IH. Stockley's drug interactions: a source book of interactions, their mechanisms, clinical importance, and management. London: Pharmaceutical Press; 2013.

18. Etminan M, Hemmelgarn B, Delaney JAC, Suissa S. Use of lithium and the risk of injurious motor vehicle crash in elderly adults: case-control study nested within a cohort. BMJ. 2004;328:558-9.

19. Breslow NE. Statistics in epidemiology: the casecontrol study. J Am Stat Assoc. 1996;91:14-28.

20. Dubois S, Bédard M, Weaver B. The impact of benzodiazepines on safe driving. Traffic Inj Prev. 2008;9:404-13.

21. Dassanayake T, Michie P, Carter G, Jones A. Effects of benzodiazepines, antidepressants and opioids on driving: a systematic review and meta-analysis of epidemiological and experimental evidence. Drug Saf. 2011;34:125-56.

22. Van Laar MW, van Willigenburg AP, Volkerts ER. Acute and subchronic effects of nefazodone and imipramine on highway driving, cognitive functions, and daytime sleepiness in healthy adult and elderly subjects. J Clin Psychopharmacol. 1995;15:30-40.

23. Vanakoski J, Mattila MJ, Seppälä T. Driving under light and dark conditions: effects of alcohol and diazepam in young and older subjects. Eur J Clin Pharmacol. 2000;56:453-8.

24. Leufkens TRM, Vermeeren A. Highway driving in the elderly the morning after bedtime use of hypnotics: a comparison between temazepam $20 \mathrm{mg}$, zopiclone $7.5 \mathrm{mg}$, and placebo. J Clin Psychopharmacol. 2009;29:432-8.

25. Kuitunen T. Drug and ethanol effects on the clinical test for drunkenness: single doses of ethanol, hypnotic drugs and antidepressant drugs. Pharmacol Toxicol. 1994;75:91-8. 